\title{
A case of pneumothorax following bougie-guided intubation in a patient undergoing excision of an intraventricular space occupying lesion
}

\author{
Ramanan Rajagopal, Veena Jayaseelan, Mathew George
}

\begin{abstract}
A 46-year-old female with intraventricular space occupying lesion was posted for craniotomy and excision of the same. Immediately following routine induction of general anaesthesia and a bougie-guided intubation, she developed increased airway pressures and desaturation associated with a decreased air entry on the right side of the chest suggestive of a right-sided pneumothorax which was confirmed with radio imaging and following the placement of chest drain the saturation improved and airway pressures decreased. To be faced with a pneumothorax following an intubation could be surprising for a non-suspecting anaesthesiologist and it can have important implications especially in neurosurgical cases where a tight control of intracranial pressure is warranted. Hence, this case report emphasises the need for a high index of clinical suspicion for proper management and safe patient outcome.
\end{abstract}

Key words: Chest tubes, general anaesthesia, pneumothorax

\section{INTRODUCTION}

Pneumothorax following routine induction of general anaesthesia (GA) is a rare event $(0.1 \%)^{[1]}$ and has been reported with difficult intubation, double lumen endotracheal tube placement and ARDS patients on a ventilator, following feeding tube placement, etc. ${ }^{[2-4]} \mathrm{We}$ report a rare case of pneumothorax following routine induction of GA followed by a bougie-guided intubation necessitating an intercostal drain (ICD), which might be deleterious in neurosurgical anaesthesia if not identified early.

Department of Anaesthesiology and Critical Care, Amrita Institute of Medical Sciences, Kochi, Kerala, India

Address for correspondence:

Dr. Ramanan Rajagopal, Amrita Institute of Medical Sciences, Kochi, Kerala, India.

E-mail: ramanashiva@gmail.com

\begin{tabular}{|l|l|}
\hline \multicolumn{2}{|c|}{ Access this article online } \\
\hline Quick Response Code: & Website: \\
\hline & www.jnaccjournal.org \\
\cline { 2 - 3 } & \\
\hline
\end{tabular}

\section{CASE REPORT}

A 46-year-old female presented to our hospital with a 2-month history of a headache and vomiting. Her Glasgow coma scale was 15/15; pupils were bilaterally equal, no neurological deficits with stable vitals measuring a heart rate of 78 and a blood pressure (BP) of 130/80 $\mathrm{mm} \mathrm{Hg}$. Her weight was $73 \mathrm{~kg}$ and height $150 \mathrm{~cm}$ and had a Mallampati score of I with a normal neck extension and flexion. Pre-operative workup showed an intraventricular space occupying lesion. Her investigations including pre-operative chest $\mathrm{X}$-ray were within normal range and did not show any emphysematous bulla. She was posted for excision of the tumour (Poppen's approach) under GA and was accepted under the American Society of Anaesthesiologists Physical Status I.

After attaching the standard monitors including pulse oximetry, non-invasive BP and electrocardiogram,

This is an open access article distributed under the terms of the Creative Commons Attribution-NonCommercial-ShareAlike 3.0 License, which allows others to remix, tweak, and build upon the work non-commercially, as long as the author is credited and the new creations are licensed under the identical terms.

For reprints contact: reprints@medknow.com

How to cite this article: Rajagopal R, Jayaseelan V, George M. A case of pneumothorax following bougie-guided intubation in a patient undergoing excision of an intraventricular space occupying lesion. J Neuroanaesthesiol Crit Care 2017;4:117-9. 
anaesthesia was induced with a sleep dose of propofol, fentanyl $2 \mathrm{mcg} / \mathrm{kg}$ body weight and vecuronium $8 \mathrm{mg}(0.1 \mathrm{mg} / \mathrm{kg})$. Direct laryngoscopy revealed a Cormack-Lehane Grade II, and a gum elastic bougie was passed through the glottic opening under vision and a $7.5 \mathrm{~mm}$ cuffed flexometallic endotracheal tube was railroaded over the bougie in a single attempt.

Immediately, following intubation, it was noticed that the airway pressure was high in the range of $40-45 \mathrm{~cm}$ $\mathrm{H}_{2} \mathrm{O}$, there was no air entry on the right side and the right hemithorax had a hyper-resonant note to percussion. The patient desaturated to $80 \%$ with $40 \%$ oxygen in air and needed $100 \%$ oxygen to maintain saturation $\left(\mathrm{SpO}_{2}\right)$ of $95 \%$ using manual bag ventilation due to high airway pressures. Pneumothorax was suspected and a C-arm imaging done revealed a right-sided massive pneumothorax [Figure 1]. Immediately, a chest tube was placed [Figure 2] following which the airway pressures decreased to $22 \mathrm{~cm} \mathrm{H}_{2} \mathrm{O}$ and the saturations improved to $100 \%$ with $40 \%$ oxygen. Throughout the period, the patient remained haemodynamically stable. The surgery was deferred and an endoscopic third ventriculostomy was done to decrease the intracranial pressure (ICP), and the patient was electively ventilated for a few hours and trachea was extubated. Fiberoptic bronchoscopy done through the endotracheal tube and high resolution computed tomography (CT) were done to look for a tracheobronchial tear which could have attributed to the pneumothorax, but it failed to give a conclusive evidence. Her post-operative course was uneventful and a chest X-ray done on a post-operative day 5 after removal of the ICD was normal and she was rescheduled for surgery on a later day.

\section{DISCUSSION}

Common causes of pneumothorax following GA include placement of double lumen tube, intubation in neonates,

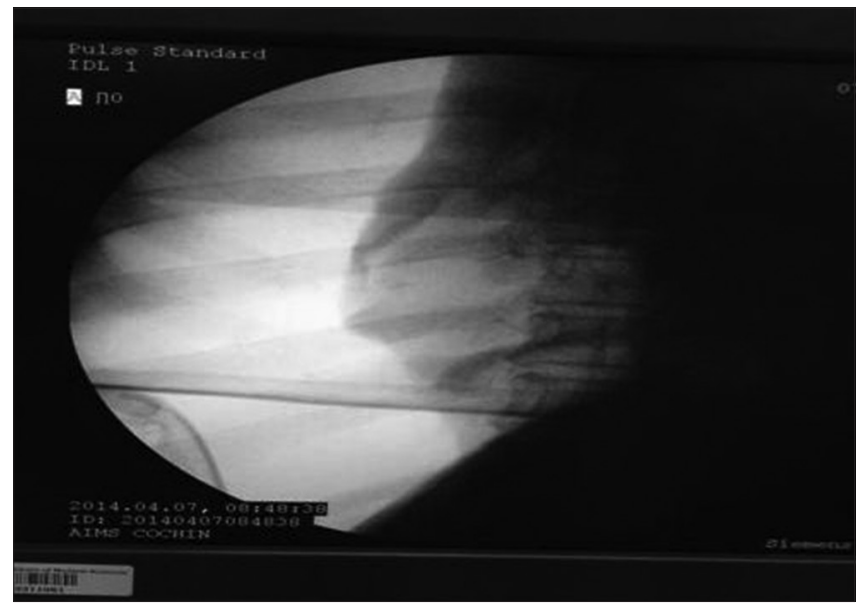

Figure 1: Right-sided pneumothorax following intubation difficult intubation or repeated attempts at intubation and use of style, in patients receiving jet ventilation. ${ }^{[2-8]}$ Pneumothorax has also been reported as a post-operative complication following uneventful GA.${ }^{[9]}$ Established risk factors include female gender, age $>50$, use of double lumen tubes, gross over inflation of cuff. Probable risk factors include corticosteroid use, tracheomalacia, poor general medical condition, misuse of stylet. ${ }^{[9]}$

In women, anatomical and technical factors may be responsible for causing tracheal tears including downward displacement of the tube too far into a short trachea, use of oversized tubes and weakness of trachea. ${ }^{[8]}$ Female patients, short stature and obesity are some risk factors associated with this complication. Pneumothorax with its associated increases in peak airway pressures can indirectly increase the ICP, which will be associated with deleterious outcomes in patients undergoing neurosurgery. ${ }^{[10]}$

The mechanisms of pneumothorax following tracheal intubation are high positive pressure during mechanical ventilation, and the mechanism is primarily the dissection of air along the perivascular sheath of the pulmonary artery presumably due to rupture of perivascular alveoli. ${ }^{[1]]}$

In a retrospective study of 19 patients treated for iatrogenic tracheobronchial lesions, $11(58 \%)$ had a single lumen tube, $4(21 \%)$ had a double lumen tube and $2(10 \%)$ by tracheal cannula, the post-operative mortality was $42 \%$, which was not dependent on the rupture but basically by the underlying disease requiring intubation. ${ }^{[12]}$

The cause of pneumothorax, in this case, could be due to a tracheobronchial mucosal tear following insertion of bougie, which was not big enough to be identified by bronchoscopy or high-resolution $\mathrm{CT}$, but

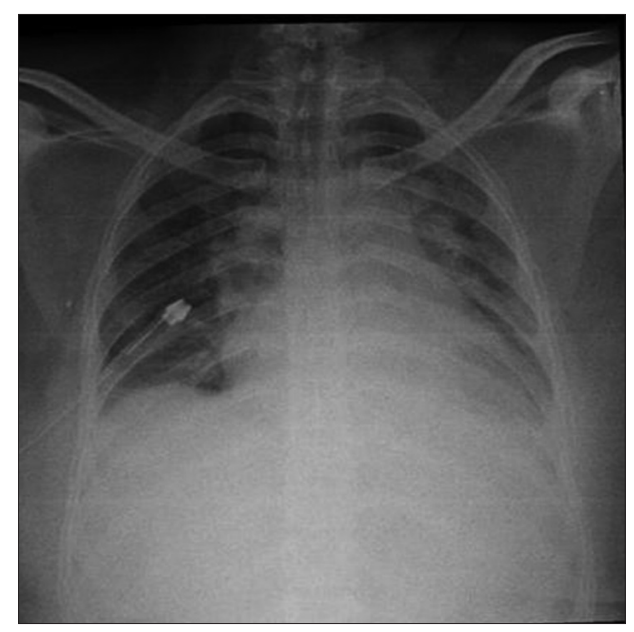

Figure 2: Intercostal drain tube in situ and a good lung expansion 
the positive pressure ventilation could have worsened the pneumothorax. Suspicion of pneumothorax is purely clinical and the common findings include increased airway pressures, decreased air entry in the corresponding hemithorax, desaturation and hypotension. Chest X-ray (CXR), CT scan or lung ultrasound can aid in making a diagnosis. The diagnosis is confirmed with a chest X-ray or CT scan. Since this patient did not reveal any major tracheobronchial tear on bronchoscopy and the air leak settled after placement of an ICD, she was managed conservatively.

Although pneumothorax following routine induction of GA is a rare entity, haemodynamic instability, desaturation and higher airway pressures should alert the anaesthesiologist in suspecting it. Lung ultrasound or a CXR is an easy and quick on table method to diagnose pneumothorax. ${ }^{[10]}$ It should also be stressed that in bougie-guided intubations, the bougie should be stabilised while the endotracheal tube is advanced to avoid tracheobronchial injury.

\section{Financial support and sponsorship}

Nil.

\section{Conflicts of interest}

There are no conflicts of interest.

\section{REFERENCES}

1. Martin LD, Mhyre JM, Shanks AM, Tremper KK, Kheterpal S. 3,423 emergency tracheal intubations at a university hospital: Airway outcomes and complications. Anesthesiology 2011;114:42-8.

2. de Almeida JP, Hajjar LA, Fukushima JT, Nakamura RE,
Albertini R, Galas FR. Bronchial injury and pneumothorax after reintubation using an airway exchange catheter. Braz J Anesthesiol 2013;63:107-9.

3. Hensel M, Marnitz R. Pneumothorax following nasogastric feeding tube insertion: Case report and review of the literature. Anaesthesist 2010;59:229-32, 234.

4. Zausig YA, Graf BM, Gust R. Occurrence of a pneumothorax secondary to malpositioned nasogastric tube: A case report. Minerva Anestesiol 2008;74:735-8.

5. Nunn C, Uffman J, Bhananker SM. Bilateral tension pneumothoraces following jet ventilation via an airway exchange catheter. J Anesth 2007;21:76-9.

6. Chen WY, Lin JA, Chen HL, Wong CS, Ho ST, Lu CC. Pneumothorax associated with tube exchanger-aided intubation following LMA-Fastrach placement in a patient during anesthesia induction. Acta Anaesthesiol Taiwan 2004;42:227-31.

7. Sucato DJ, Girgis M. Bilateral pneumothoraces, pneumomediastinum, pneumoperitoneum, pneumoret roperitoneum, and subcutaneous emphysema following intubation with a double-lumen endotracheal tube for thoracoscopic anterior spinal release and fusion in a patient with idiopathic scoliosis. J Spinal Disord Tech 2002;15:133-8.

8. Biswas C, Jana N, Maitra S. Bilateral pneumothorax following tracheal intubation. Br J Anaesth 1989;62:338-9.

9. Chen EH, Logman ZM, Glass PS, Bilfinger TV. A case of tracheal injury after emergent endotracheal intubation: A review of the literature and causalities. Anesth Analg 2001;93:1270-1.

10. Ludwig HC, Klingler M, Timmermann A, Weyland W, Mursch K, Reparon $\mathrm{C}$, et al. The influence of airway pressure changes on intracranial pressure (ICP) and the blood flow velocity in the middle cerebral artery (VMCA). Anasthesiol Intensivmed Notfallmed Schmerzther 2000;35:141-5.

11. Berg LF, Mafee MF, Campos M, Applebaum EL. Mechanisms of pneumothorax following tracheal intubation. Ann Otol Rhinol Laryngol 1988;97:500-5.

12. Zlotnik A, Gruenbaum SE, Gruenbaum BF, Dubilet $M$, Cherniavsky E. Iatrogenic tracheobronchial rupture: A case report and review of the literature. Int J Case Rep Images 2011;2:12-6. 